\title{
O conceito de risco nas resoluções brasileiras que regulamentam a revisão ética da
}

\section{pesquisa envolvendo seres humanos}

The concept of risk in Brazilian resolutions that regulate the ethical review of research involving human beings

El concepto de riesgo en las resoluciones brasileñas que regulan la revisión ética de la investigación con seres humanos

Recebido: 09/05/2021 | Revisado: 16/05/2021 | Aceito: 04/06/2021 | Publicado: 20/06/2021

Pedro Bruno Silva Lemos
ORCID: https://orcid.org/0000-0001-7235-9846
Universidade da Integração Internacional da Lusofonia Afro-Brasileira, Brasil
E-mail: pedrolemos@unilab.edu.br
Francisco José Alves de Aquino
ORCID: https://orcid.org/0000-0003-2963-3250
Instituto Federal de Educação, Ciência e Tecnologia do Ceará, Brasil
E-mail: fcalves.aq@ifce.edu.br

\begin{abstract}
Resumo
O presente artigo analisou o conceito de risco nas normativas brasileiras sobre ética na pesquisa envolvendo seres humanos. Em termos metodológicos, este trabalho foi desenvolvido através de uma pesquisa do tipo bibliográfica e documental, centrada em uma abordagem de análise dos dados, prioritariamente, qualitativa. O objetivo principal desse trabalho foi abordar como cada normativa brasileira a respeito dos aspectos éticos na pesquisa que pressuponha a participação de seres humanos conceituou risco e estabeleceu critérios que possibilitassem a sua análise ética e mensuração. Evidenciou-se, portanto, a importância/centralidade do conceito de risco para a apreciação ética realizado pelo Sistema CEP/CONEP. Ademais, observou-se que as resoluções vigentes, Resoluções CNS n 466/2012 e $n^{\circ} 510 / 2016$, estabelecem uma gradação dos riscos da pesquisa com seres humanos em níveis. Nesse sentido, salientou-se que as mencionadas resoluções condicionam a tramitação dos protocolos à gradação dos riscos mensurados. No entanto, constatou-se que as normativas éticas vigentes não definem os critérios que orientariam o processo de tipificação e gradação dos riscos na pesquisa com seres humanos. Por fim, ressaltou-se que as duas resoluções vigentes fazem referência à diretriz ética do CNS que versaria a respeito dos critérios para mensuração dos níveis de riscos na pesquisa envolvendo seres humanos, porém constatou-se que essa normativa ainda não foi elaborada.
\end{abstract}

Palavras-chave: Ética em pesquisa; Experimentação humana; Avaliação de risco e mitigação; Comitês de ética em pesquisa.

\begin{abstract}
This article analyzed the concept of risk in Brazilian regulations on ethics in research involving human beings. In methodological terms, this work was developed through bibliographic and documentary research, centered on a data analysis approach, primarily a qualitative one. The main objective of this work was to address how each Brazilian normative regarding ethical aspects in research that presupposes the participation of human beings conceptualized risk and established criteria that would allow its ethical analysis and measurement. It was evident, therefore, the importance/centrality of the concept of risk for the ethical assessment carried out by the CEP/CONEP System. In addition, it was observed that the current resolutions, Resolutions CNS $n^{\circ} 466 / 2012$ and $n^{\circ}$ 510/2016, establish a gradation of the risks of research with human beings in levels. In this sense, it was emphasized that the aforementioned resolutions condition the processing of protocols to the gradation of the measured risks. However, it was found that the current ethical standards do not define the criteria that would guide the process of risk classification and grading in research with human beings. Finally, it was emphasized that the two current resolutions refer to the CNS ethical guideline that would deal with the criteria for measuring risk levels in research involving human beings, but it was found that this standard has not yet been developed.
\end{abstract}

Keywords: Research ethics; Human experimentation; Risk evaluation and mitigation; Ethics committees, Research.

\section{Resumen}

Este artículo analizó el concepto de riesgo en la normativa brasileña sobre ética en la investigación con seres humanos. En términos metodológicos, este trabajo se desarrolló a través de una investigación bibliográfica y 
documental, centrada en un enfoque de análisis de datos, principalmente cualitativo. El objetivo principal de este trabajo fue abordar cómo cada normativa brasileña sobre aspectos éticos en la investigación que presupone la participación del ser humano conceptualiza el riesgo y establece criterios que permitan su análisis y medición ética. Se evidenció, por tanto, la importancia/centralidad del concepto de riesgo para la evaluación ética que realiza el Sistema CEP/CONEP. Además, se observó que las resoluciones vigentes, las Resoluciones CNS n 466/2012 y n 510/2016, establecen una gradación de los riesgos de la investigación con seres humanos en niveles. En este sentido, se enfatizó que las resoluciones mencionadas condicionan la tramitación de protocolos a la gradación de los riesgos medidos. Sin embargo, se encontró que los estándares éticos vigentes no definen los criterios que orientarían el proceso de clasificación y graduación de riesgos en la investigación con seres humanos. Finalmente, se enfatizó que las dos resoluciones vigentes se refieren a la directriz ética del SNC que abordaría los criterios para medir niveles de riesgo en investigaciones con seres humanos, pero se encontró que esta norma aún no se ha desarrollado.

Palabras clave: Ética en investigación; Experimentación humana; Evaluación y mitigación de riesgos; Comités de ética en investigación.

\section{Introdução}

A palavra risco, de maneira geral, é definida nos dicionários como um substantivo masculino que conceitua a probabilidade de insucessos ou prejuízos em determinada ação ou projeto, em decorrência de um evento de ocorrência incerta (Ferreira, 2010). Na linguagem coloquial, entretanto, esse termo é constantemente associado à possibilidade de um efeito negativo, em outras palavras, o risco é compreendido como um sinônimo de ameaça, dano, perda ou perigo.

Em termos etimológicos, a origem do conceito de risco remonta ao italiano antigo, especificamente, ao verbo "risicare" que significa "ousar" ou "arriscar" (Bernstein, 1997; La Mendola, 2005). Desse modo, observa-se que a origem etimológica do mencionado conceito faz referência ao enfrentamento da incerteza na busca por um objetivo específico, ou seja, à possibilidade/probabilidade da ação ou da atividade humana alcançar um objetivo almejado (efeito positivo) ou ocasionar um possível dano (efeito negativo) (La Mendola, 2005).

O risco, portanto, é um aspecto onipresente na existência humana, pois qualquer ação, mesmo que involuntária, pressupõe, em nível individual e/ou coletivo, alguma incerteza em relação ao efeito ou resultado que será alcançado (Bernstein, 1997; Damodaran, 2008). Desse modo, a análise dos riscos inerentes a cada ação ou atividade tornou-se algo fundamental para a humanidade (Damodaran, 2008).

Nas sociedades antigas, todavia, o risco era algo incompreensível e que moldava o futuro do homem, conforme os caprichos ou desejos das divindades. Para Bernstein (1997), o domínio do risco definiu a fronteira histórica entre as sociedades arcaicas e as sociedades modernas, pois possibilitou ao homem definir os possíveis impactos de suas ações e escolher racionalmente a alternativa mais adequada ou menos danosa.

A concepção de risco como um aspecto da ação humana passível de uma análise racional surge com a implementação do sistema de numeração indo-arábico (Bernstein, 1997). Contudo, é somente no Renascimento, com o desenvolvimento do método de experimentação, e com a utilização de instrumentos técnicos, que os riscos passam a ser mensurados quantitativamente e estudados de forma científica.

Em decorrência do seu caráter multidimensional intrínseco, bem como da sua onipresença em toda a atividade humana, hodiernamente, o risco tornou-se o objeto de estudo de inúmeros campos de conhecimento. Nos diferentes campos de pesquisa, a utilização do conceito de risco busca, em regra, traduzir a complexidade e as incertezas inerentes às tomadas de decisões e/ou às análises de determinados fenômenos, como exemplo, pode-se mencionar as seguintes formas de utilização desse conceito: gestão de risco, o risco social, o risco ambiental, o risco de saúde etc.

A utilização do conceito de risco pode variar dentro de um amplo espectro de significados. Desse modo, Damodaran (2008) salienta que, em determinadas áreas de conhecimentos, a utilização do conceito de risco encontra-se vinculada, essencialmente, à probabilidade de ocorrência de eventos danosos ou negativos; enquanto outras áreas utilizam esse conceito 
para caracterizar a sucessão de eventos que podem ocasionar tanto perdas como ganhos. Nas palavras do referido autor, "[...] o risco oferece oportunidades ao mesmo tempo em que nos expõe a resultados talvez indesejáveis” (Damodaran, 2008, p. 27).

No que diz respeito à análise científica, o risco caracteriza a possibilidade da ocorrência de erros ou falhas conceituais, metodológicos, teóricas, epistemológicos, dentre outras - que impossibilitem ou alterem a obtenção de um resultado preestabelecido. Na atividade científica, o risco também pode caracterizar a probabilidade de implicações e os danos/impactos ocasionados pela realização e/ou pelos resultados de um estudo.

No caso da pesquisa com humanos, a noção de risco relaciona-se, em adicional, à uma dimensão ética da prática científica, uma vez que os possíveis danos ou benefícios resultantes da execução de um estudo podem impactar diretamente na integridade física, psíquica, moral, intelectual, social, cultural ou espiritual dos participantes. Sendo assim, o mencionado conceito traduz a probabilidade de toda atividade de pesquisa com seres humanos causar danos aos participantes (Vieira \& Hossne, 1987).

Destarte, a ética na pesquisa que pressupõe os seres humanos como objeto de análise surge com a missão principal de proteger os participantes de possíveis danos ocasionados pela participação voluntária em estudos científicos (Kottow, 2008). Nessa perspectiva, constata-se que a análise dos possíveis riscos se torna fundamental para que a efetuação dos estudos científicos caminhe junto com a proteção eficiente dos participantes.

A análise ética da pesquisa com seres humanos pressupõe que os pesquisadores envolvidos, especificamente, o pesquisador principal realize um prévio levantamento dos riscos decorrentes da participação na pesquisa, assim como elabore medidas ou ações que objetivem minimizar esses riscos e, de maneira consequente, garantir a integridade dos participantes (Guilhem \& Diniz, 2017). Ademais, a forma de esclarecimento dos sujeitos a respeito dos possíveis riscos ou benefícios resultantes da participação no estudo é imprescindível para a adequação ética da atividade de pesquisa (Resoluções CNS $n^{\circ}$ 466, 2012).

Também é necessário ratificar que, na revisão/ análise ética de pesquisas/estudos com seres humanos, os riscos podem variar conforme a temática do estudo, o desenho metodológico adotado, principalmente, a forma de coleta/registro de dados, o método de abordagem dos participantes, os objetivos e a forma com os dados serão analisados. Cabe mencionar, de maneira complementar, que o participante não deve ser exposto a riscos desnecessários, ou seja, a riscos maiores que os benefícios resultantes da participação na pesquisa (Kottow, 2008).

Ante o exposto, é possível constatar que a noção de risco presente nas normativas que regulamentam a revisão ética dos estudos científicos com seres humanos subsidia tanto a análise dos aspectos éticos das pesquisas, bem como a prévia etapa de definição e de mensuração dos riscos. Sendo assim, o presente artigo buscou analisar e discutir o conceito de risco estabelecido pela normativas brasileiras que disciplinam a ética na pesquisa. Portanto, o interesse principal desse trabalho foi abordar como cada normativa brasileira, a respeito dos aspectos éticos na pesquisa que pressuponha a participação de seres humanos, conceituou o risco e definiu os critérios que possibilitassem a sua análise ética e mensuração.

\section{Metodologia}

No que diz respeito aos aspectos metodológicos, o presente trabalho é classificado como um estudo centrado em uma abordagem de análise de dados do tipo qualitativa, realizado por meio de uma pesquisa bibliográfica e documental. A pesquisa qualitativa não busca investigar um fenômeno ou um objetivo através de uma análise numérica, pelo contrário, privilegia a descrição dos aspectos não quantificáveis (Moura, Silva, Silva, Sousa, \& Albuquerque, 2021). Nesse sentido, Silveira e Córdova (2009) salientam que os estudo de cunho qualitativo privilegiam a análise dos "[...] aspectos da realidade que não podem ser quantificados, centrando-se na compreensão e explicação da dinâmica das relações sociais" (Silveira \& Córdova, 2009, p. 32). 
Portanto, a pesquisa qualitativa objetiva fornecer explicações aos questionamentos que não podem ser respondidos de forma quantificável (Cardano, 2017; Moura, Silva, Silva, Sousa, \& Albuquerque, 2021; Taquette, \& Borges, 2021). Nesse sentido, compreende-se que essa abordagem "[...] trabalha universo de significados, motivos, aspirações, crenças, valores e atitudes, o que corresponde a um espaço mais profundo das relações, dos processos e dos fenômenos que não podem ser reduzidos à operacionalização de variáveis" (Minayo, 2002, p. 21-22). Sendo assim, nosso estudo buscou, por meio de um enfoque qualitativo, analisar o conceito de risco presente nas normativas nacionais sobre ética em pesquisa, buscando observar e discutir a significação desse conceito em cada uma das normativas examinadas.

Em relação à pesquisa bibliográfica e documental, Cechinel, Fontana, Della, Pereira, e Prado (2016) e Gil (2008) ponderam que a pesquisa bibliográfica tem como foco de análise materiais que receberam tratamento analítico, por exemplo, artigos científicos, livros, teses e dissertações, enquanto a pesquisa documental é pautada na análise de leis, resoluções, relatórios, dentre outros documentos que não receberam um tratamento analítico no decorrer do seu processo de elaboração.

Isto posto, convém ressaltar que o presente artigo objetivou realizar uma pesquisa bibliográfica em artigos científicos e livros acerca do conceito de risco na pesquisa que pressuponha a participação de seres humanos. A seleção dos artigos e livros ocorreu mediante busca nas seguintes bases online de dados científicos: Google Acadêmico, Scientific Eletronic Library Online (SciELO) do Brasil e Literatura Latino-Americana e do Caribe em Ciências da Saúde (LILACS). A identificação dos trabalhos acadêmicos nas mencionadas bases de dados foi realizada por meio dos seguintes descritores: "ÉTICA EM PESQUISA", "ÉTICA NA PESQUISA", "PESQUISA COM SERES HUMANOS”, "EXPERIMENTAÇÃO HUMANA" e "PESQUISA ENVOLVENDO SERES HUMANOS". No decorrer do processo de seleção dos artigos científicos e livros, privilegiou-se os trabalhos publicados nos últimos cincos anos (2016-2021), assim como os trabalhos publicados há mais de cinco anos, mas que são referências para as pesquisas que abordam os aspectos éticos da prática científica com seres humanos.

De maneira complementar, realizou-se, ainda, uma pesquisa documental nas resoluções que regulamentam a verificação ética executada pelas instâncias que compõem o sistema nacional de checagem ética. A pesquisa documental foi realizada, prioritariamente, nos sites da Comissão Nacional de Ética em Pesquisa (CONEP) e do Conselho Nacional de Saúde (CNS). Além das normativas brasileiras, também foram coletadas normativas internacionais a respeito da regulação ética da experimentação humana.

\section{Discussões}

\section{1 Ética na pesquisa: breve histórico}

Os registros históricos evidenciam a presença da experimentação/pesquisa com humanos em díspares contextos sociais e culturais (Vieira \& Hossne, 1987). Depreende-se, em adicional, que o surgimento e a ascensão das Ciências Biomédicas, portanto, estão intrinsecamente relacionados às práticas de experimentação em humanos (Bento, 2011; Vieira \& Hossne, 1987).

É consenso, destarte, que a prática de experimentação em humanos assume uma importância central para o estabelecimento das sociedades modernas. Adicionalmente, Araújo e Alegria (2016) também enfatizam que:

Os procedimentos experimentais e científicos que atribuem ao ser humano a condição de sujeito de pesquisa, atualmente representam o instrumento mais utilizado na busca por descobertas médicas e, principalmente, por avanços na indústria farmacêutica. Nesse sentido, o ser humano vem se submetendo a tratamentos cujos procedimentos e efeitos desconhece, visando benefícios de ordens diversas (Araújo \& Alegria, 2018, p. 183).

Entretanto, mesmo considerando sua relevância social, cabe mencionar que a história da experimentação com seres humanos é sublinhada pela execução de diversos estudos antiéticos que causaram danos irreversíveis ou o óbito de inúmeros indivíduos (Araújo, 2008; Bento, 2011; Vieira \& Hossne, 1987). Conforme salientam Araújo (2008), Guilhem e Diniz (2017), 
bem como Vieira e Hossne (1987), a inexistência de normativas ou legislações que regulamentassem a prática científica que pressuposse a participação de sujeitos foi o principal fator que contribuiu para a presença de agravos e excessos em estudos com seres humanos.

As primeiras orientações nacionais sobre ética em pesquisa foram publicadas, em 1900, pelo Ministério da Saúde da Prússia (Barros \& Barros, 2009; Capron, 1989). Essa primeira tentativa de normatização da experimentação com humanos estabelecia a necessidade de o pesquisador adotar uma postura moral e íntegra em relação aos participantes e à execução da pesquisa, assim como a obrigatoriedade do consentimento explícito dos pesquisados, após terem acesso às informações acerca dos possíveis riscos e consequências da participação no experimento. Contudo, ressalta-se que esse primeiro documento teve uma repercussão estritamente local, sendo adotado exclusivamente por pesquisadores de determinadas regiões da Prússia (Souza, 2008).

Em 1931, em decorrência da limitada repercussão do documento de 1900, o Ministro do Interior da Alemanha promulgou as Diretrizes para Novas Terapêuticas e Pesquisa em Seres Humanos (Capron, 1989). Essas diretrizes estabeleceram os padrões éticos da experimentação com seres humanos de maneira detalhada, ampliando as exigências éticas presentes no documento de 1900 (Sass, 1983; Souza, 2008).

Desse modo, observa-se que as Diretrizes para Novas Terapêuticas e Pesquisa em Seres Humanos estabeleceram a obrigatoriedade da prévia análise dos riscos, de explicações documentadas para qualquer alteração na proposta de pesquisa inicial, de justificativas coerentes para a realização de experimentos com pacientes vulneráveis e crianças, bem como a necessidade do pesquisador dispor de documentação escrita sobre a pesquisa (Capron, 1989; Souza, 2008). No entanto, cabe frisar que, apesar de apresentarem uma ampla e detalhada regulamentação ética da pesquisa com seres humanos, as Diretrizes para Novas Terapêuticas e Pesquisa em Seres Humanos não impediram a realização de experimentos antiéticos no decorrer do período nazista (Capron, 1989; Souza, 2008).

Isto posto, é significativo mencionar que os primeiros debates internacionais acerca da regulamentação ética da pesquisa com seres humanos surgem em resultância da divulgação dos abusos e atrocidades cometidos nos campos de concentração por pesquisadores nazistas no decorrer da II Guerra Mundial (Guilhem \& Diniz, 2017). Como resultado, no dia 19 de agosto de 1947, foi publicado o Código de Nuremberg, primeira normativa internacional orientada para a regulamentação ética da ciência (Guilhem \& Diniz, 2017).

A subvenção preponderante do Código de Nuremberg para o estabelecimento da revisão ética da pesquisa com humanos, enquanto disciplina, foi a imposição obrigatória do prévio consentimento dos sujeitos para a execução da pesquisa (Kottow, 2008). Outras importantes contribuições dessa normativa internacional foram: a compulsoriedade do responsável pelo estudo promover a salvaguarda dos indivíduos contra qualquer risco decorrente da participação na pesquisa; a exigência de qualificação dos pesquisadores; e a compulsoriedade do balanço favorável na relação "grau de risco-resultados vantajosos".

Todavia, a principal limitação do Código de Nuremberg foi atribuir a responsabilidade acerca da verificação dos riscos unicamente ao pesquisador responsável pelo estudo (Fonseca, 2015). Outra limitação que também corroborou para a pouca adesão dos pesquisadores ao referido documento internacional foi a sua caracterização como somente uma resposta aos crimes cometidos na II Guerra Mundial (Guilhem \& Diniz, 2017; Kipper, 2010).

Apesar de ter surgindo com a primeva normativa a abordar a imprescindibilidade da regulamentação ética na pesquisa biomédica em âmbito internacional, o Código de Nuremberg não coibiu o elevado quantitativo de estudo biomédicos que desrespeitaram os direitos dos indivíduos. Essa realidade acompanhada pela regularidade de denúncias a respeito excessos realizados por pesquisadores de inúmeros países, sublinharam a indispensabilidade da criação de ordenamentos éticos internacionais mais amplos (Kipper, 2010; Silva \& Portela, 2016). 
Com o propósito de produzir uma diretriz que promovesse uma regulação ética mais ampla dos estudos que previssem experimentações biomédicas com humanos, assim como considerando o diminuto reconhecimento do Código de Nuremberg por parte dos pesquisadores, principalmente, das Ciências Biomédicas, a Associação Médica Mundial (AMM) publicou, no mês de junho de 1964, a Declaração de Helsinque. A referida normativa estabelece como requisito obrigatório para a execução da pesquisa biomédica que envolve a experimentação em seres humanos a presença de benefícios maiores que a probabilidade de riscos. Por conseguinte, a primeira versão e as demais versões da Declaração de Helsinque ${ }^{1}$ estatuem, de maneira complementar, que os riscos devem ser constantemente mensurados e que a implementação de medidas para minimizá-los é obrigação do pesquisador.

Toda pesquisa médica envolvendo seres humanos deve ser precedida por avaliação cuidadosa dos riscos e ônus previsíveis aos indivíduos e grupos envolvidos na pesquisa em comparação com os benefícios esperados para eles e para outros indivíduos ou grupos afetados pela condição sob investigação. Medida para minimizar os riscos devem ser implementadas. Os riscos devem ser continuadamente monitorados, avaliados e documentados pelo pesquisador (Declaração de Helsinque, 2013, p. 2).

A aceitação exitosa da Declaração de Helsinque, em âmbito internacional, contribuiu para a maior adequação ética das pesquisas biomédicas, da mesma forma que subsidiou a posterior elaboração de legislações nacionais que objetivavam a regulamentação da prática cientifica com seres humanos (Kipper, 2010). Diante desse contexto, a National Commission for the Protection of Human Subjects of Biomedical and Behavioral Research (NCPHSBBR), instituída pelo Governo dos Estados Unidos, publicou, no ano de 1978, o "Belmont Report: Ethical Principles and Guidelines for the Protection of Human Subjects of Research".

Embora tenha surgido como uma normativa nacional, o Relatório de Belmont, título traduzido para o português, proporcionou uma profunda alteração no debate internacional a respeito da regulação ética dos estudos biomédicos e de outros campos de conhecimento, pois estabeleceu uma série de princípios éticos que orientariam a prática da pesquisa com seres humanos, a saber: o princípio do respeito às pessoas, o princípio da beneficência e o princípio da justiça. Convém destacar que os princípios estabelecidos pelo Relatório de Belmont também condicionaram a implantação de sistemas de verificação ética em inúmeros países, dentre eles o Brasil.

Entretanto, a publicação de regulamentos éticos internacionais e a definição de uma série de princípios éticos não proporcionaram uma diminuição na execução de pesquisas ou estudos que violavam a integridade dos participantes. O principal aspecto que contribuiu para essa ocorrência de pesquisas antiéticas foi a concentração da etapa de definição e a análise dos riscos exclusivamente nas mãos dos pesquisadores.

Para proporcionar uma análise imparcial dos riscos resultantes da execução das pesquisas e, consequentemente, promover uma maior proteção dos participantes, a AMM, em assembleia realizada no ano de 1975, em Tóquio, outorgou uma proposta de alteração de Declaração de Helsinque. A partir da atualização de 1975, a Declaração de Helsinque tornou obrigatória a prévia checagem dos aspectos éticos de todas as pesquisas/estudos que envolvessem seres humanos por órgãos colegiados independentes e multidisciplinares.

É importante frisar que a compulsoriedade da prévia avaliação ética das pesquisas que pressupunha o envolvimento de seres humanos por órgãos colegiados autônomos tornou-se o critério basilar para formulação das posteriores normativas éticas, assim como para a configuração dos sistemas nacionais de revisão ética (Cardoso, Gomes, \& Rocha, 2018, Lemos et al, 2019).

\footnotetext{
${ }^{1}$ A Declaração de Helsinque foi publicada, originalmente, em 1964, porém essa normativa internacional foi revisada sete vezes. A primeira revisão ocorreu em 1975, durante a $29^{a}$ Assembleia da AMM realizada na cidade de Tóquio, Japão. A última revisão ocorreu em 2013 , durante a $64^{a}$ Assembleia da AMM realizada na cidade de Fortaleza, Ceará, Brasil.
} 
Nesse sentido, realça-se que a revisão da Declaração de Helsinque, realizada em 1975, estabeleceu os fundamentos para a criação dos processos nacionais de análise ética desenvolvidos por Comitês Ética em Pesquisa (CEPs).

\subsection{Comitês de Ética em Pesquisa e Comissão Nacional de Ética em Pesquisa}

Os CEPs surgem em consequência da necessidade de regulação da prática científica com seres humanos por instâncias colegiadas com atuação independente (Araújo, 2003; Guilhem \& Diniz, 2017). Sendo assim, a revisão/apreciação realizada por estes órgãos colegiados objetiva promover uma avaliação ética e imparcial dos riscos que os participantes podem ser expostos (Guilhem \& Diniz, 2017).

Ainda que a mensuração inicial dos riscos seja realizada pelo pesquisador, é o CEP que executa a avaliação ética da pesquisa, podendo indicar a ocorrência de riscos que não foram pontuados pelo pesquisador (Resolução CNS n 466, 2012). Portanto, essas instâncias colegiadas atuam na adequação ética dos estudos e na defesa da integridade dos participantes (Kottow, 2008).

Guilhem e Diniz (2017) ressaltam, de maneira complementar, que a configuração do processo de apreciação ética fundamentado na atuação de órgãos colegiados independentes busca promover o permanente monitoramento ético da prática cientifica com seres humanos. Ademais, as referidas autoras frisam que a atuação ética dos CEPs contribui para o controle social da prática cientifica que pressupõe a participação de seres humanos (Guilhem \& Diniz, 2017).

Nessa mesma perspectiva, Lemos, Aquino, Silva, Jucá e Silva (2019) enfatizam que os CEPs, enquanto instâncias colegiadas e independentes responsáveis pela análise ética de pesquisas, "[...] possuem a missão de garantir a proteção dos participantes da pesquisa e promover a adoção de padrões éticos nos estudos realizados com seres humanos" (Lemos et al, 2019, p.3). Para o referido autor, a revisão e a adequação éticas, bem como a definição dos riscos e benefícios oriundos da realização da pesquisa são condicionadas pela consideração dos direitos dos participantes (Lemos et al, 2019).

Relativamente à contribuição do CEP para o gerenciamento social da prática cientifica com participante, Paiva, Costa, Dias, Lopes, Souto e Silva (2015) frisam que esses órgãos colegiados atuam em "[...] nome da sociedade para analisar e garantir que a participação na pesquisa não acarreta prejuízo ou dano ao sujeito" (Paiva et al., 2015, p. 170). Destarte, Labronici, Raimondo, Trigueiro, Raimondo-Ferraz e Ramos (2012) e Paiva et al (2015) observam que os CEPs defendem os direitos e a integridade dos indivíduos, através da análise ética das pesquisas.

De maneira geral, os CEPs, portanto, surgem com a função de considerar "[...] as condições de incerteza no desenvolvimento das pesquisas e ponderar os conflitos de maneira imparcial, sem deixar de proteger a parte mais frágil, que é quase sempre o sujeito ou a população investigados" (Araújo, 2003, p. 60). Sendo assim, a verificação ética realizada por esses órgãos colegiados é centralizada na garantia dos direitos dos participantes, por meio de uma análise imparcial dos riscos e benefícios aos quais estes poderão ser expostos.

\subsection{Sistema CEP/CONEP: histórico e configuração}

Apesar do Brasil ser signatário de todas as declarações ou documentos internacionais acerca da ética na pesquisa publicadas no decorrer da segunda metade do século XX, é consenso avaliar a implementação do Sistema CEP/CONEP como recente. Nesse sentido, afere-se que as primeiras discussões acerca da necessidade de elaboração de resoluções sobre ética na prática científica que envolva participantes surgem somente na esteira da redemocratização do país.

A primeira resolução brasileira direcionada para a normatização ética dos estudos/pesquisa com humanos foi a Resolução CNS no 1/1988, elaborada pelo CNS e publicada no dia 13 de junho de 1988. A citada normativa nacional estabeleceu, conforme o disposto nas diretrizes internacionais predecessoras, a imprescindibilidade da prévia aprovação dos 
estudos com participantes por órgãos colegiados independentes; os Comitês de Ética (CE) e de Segurança Biológica (CSB). Convém acentuar que a Resolução CNS nº 1/1988 possuía um enfoque estritamente biomédico, isto é, objetivava, exclusivamente, a normatização da pesquisa com seres humanos nas Ciências da Saúde.

A Resolução CNS nº 1/1988 também prescreveu o respeito à dignidade e à proteção do direito dos participantes como requisitos para realização de qualquer pesquisa na área de saúde. Além disto, manteve a obrigação do prévio consentimento dos sujeitos para a execução de pesquisas que submetessem o ser humano à experimentação biomédica, algo previsto nos documentos internacionais que condicionaram o seu desenvolvimento (Guilhem \& Diniz, 2017).

Contudo, contata-se que a Resolução CNS nº 1/1988, apesar de normatizar a pesquisa com seres humanos na área de saúde, possuía um direcionamento para a regulamentação ética de pesquisas farmacológicas, o que restringiu sua implementação no cenário científico brasileiro (Guilhem \& Diniz, 2017). Ademais, apercebe-se que a vinculação exclusiva dos CEs e CSBs à instituição de saúde credenciada pelo CNS limitou a atuação independente desses órgãos colegiados.

Em decorrência do limitado impacto da Resolução CNS n ${ }^{\circ}$ 1/1988, o CNS, após consultas a segmentos da sociedade civil, publicou, em 10 de outubro de 1996, a Resolução CNS n 196/96, que revogou a Resolução CNS nº 1/88. Objetivando a implementação de um mecanismo nacional de controle ético, a citada normativa estabeleceu a criação do sistema nacional de apreciação ética, o Sistema CEP/CONEP, composto por uma rede nacional de CEPs e pela CONEP.

A Resolução CNS n. ${ }^{\circ}$ 196/96 instituiu a necessidade da prévia apreciação ética realizada pelo Sistema CEP/CONEP para qualquer pesquisa em que houvesse a previsão de participação de seres humanos, independentemente da área de conhecimento (Guilhem \& Diniz, 2017). A expansão da obrigatoriedade de verificação ética e a implementação do Sistema CEP/CONEP contribuíram para a rápida institucionalização da regularização ética das pesquisas com humanos vinculadas às instituições brasileiras de ensino e/ou pesquisa (Amorim, 2019, Rippel, Medeiros, \& Maluf, 2016).

Para atualizar a Resolução CNS n. ${ }^{\circ}$ 196/1996, como também definir as atribuições, a composição e o funcionamento das instâncias que integram o Sistema CEP/CONEP, o CNS publicou, no dia 12 de dezembro de 2012, a Resolução CNS n. ${ }^{\circ}$ 466/2012. É importante mencionar que a Resolução CNS no 466/2012 atualizou e a ampliou a Resolução CNS n. ${ }^{\circ}$ 196/1996, pois, por meio de contribuições oriundas de consulta pública, aprofundou questões centrais para a apreciação ética nacional das pesquisas com seres humanos. Nesse sentido, destaca-se que a preponderante contribuição dessa normativa ética vigente é a descentralização da checagem ética, bem como o estabelecimento das atribuições e a regulamentação do funcionamento dos CEPs e da CONEP (Amorim, 2019).

Os CEPs são definidos, na Resolução CNS nº 466/2012, como colegiados de atuação independente e com relevância pública, criados em instituições/organizações de ensino e pesquisa e registrados junto à CONEP (Resolução CNS nº 466, 2012; Thomasi, 2016). A Resolução CNS n 466/2012 salienta, ainda, a atuação dos CEPs na garantia dos direitos dos participantes e na implementação de padrões éticos na ciência brasileira (Rippel, Medeiros, \& Maluf, 2016).

Em relação à composição, a Resolução CNS no 466/2012 estatui que, no mínimo, a metade dos membros que compõem os colegiados dos CEPs devem ter, preferencialmente, experiência na execução de estudos com seres humanos. É importante frisar que, para promover o controle social da análise ética, todo colegiado de CEP tem de contar com a atuação de um representante dos usuários, indicado, preferencialmente, pelos Conselhos Municipais de Saúde ou por outra entidade representativa.

A Resolução CNS no 466/2012 descreve a CONEP como um órgão colegiado independente e credenciado junto ao CNS e responsável pela gestão e normatização da análise ética desenvolvida pelo Sistema CEP/CONEP (Resolução CNS $n^{\circ}$ 466, 2012; Thomasi, 2016). Além disso, a Resolução CNS nº 466/2012 também estabelece as atribuições normativas da CONEP, assim como sua atuação na verificação ética de pesquisas de áreas temáticas especiais (Amorim, 2019). 
Os membros que compõem o colegiado da CONEP devem possuir experiência na prática científica e, preferencialmente, na realização de estudos com seres humanos (Resolução CNS nº 466, 2012). A composição da CONEP também conta com representantes dos usuários indicados por entidades representativas específicas (Resolução CNS nº 466, 2012).

Tanto os CEPs como CONEP são instâncias responsáveis pela emissão de pareceres consubstanciados que discorrem acerca dos aspectos éticos das pesquisas analisadas. A diferença é que a atuação dos CEP é local, enquanto a CONEP tem uma atuação restrita, isto é, realiza a análise ética apenas de estudos que tenham a probabilidade de causar danos elevados e permanentes aos participantes e/ou, de maneira geral, à sociedade (Resolução CNS nº 466, 2012).

Outra importante questão regulamentada pela Resolução CNS nº 466/2012 é a definição dos processos de submissão e monitoramento das pesquisas aprovadas ao Sistema CEP/CONEP (Guilhem \& Diniz, 2017). Nessa perspectiva, a resolução impõe que toda a documentação necessária para a revisão ética deve ser submetida por meio de um sistema online oficial, a saber: a da Plataforma Brasil. Cabe citar que a implementação dessa ferramenta online também possibilita à sociedade civil monitorar as pesquisas aprovados em tempo real (Resolução CNS nº 466, 2012).

Tendo em conta as crescentes e contínuas críticas acerca da orientação biomédica das Resoluções CNS nº 196/1996 e n 466/2012, o CNS publicou, no dia 24 de maio de 2016, a Resolução CNS n 510/2016 que tem um caráter complementar e objetiva regulamentar a análise da eticidade das pesquisas das Ciências Humanas e Sociais (CHS) ou de estudos que empreguem metodologias típicas dessa área de conhecimento. Loderllo e Silva (2017) e Peixoto (2016) definem a Resolução CNS n. ${ }^{\circ}$ 510/2016 como uma proposta de adequação da revisão ética realizada pelo Sistema CEP/CONEP às peculiaridades da prática cientifica nas CHS.

Segundo Guerriero (2016) e Mainardes (2017), a revisão ética nas CHS pressupõe o reconhecimento da complexidade metodológica e epistemológica típica nessa área de conhecimento. Por isso, a Resolução CNS n. ${ }^{0}$ 510/2016 avança ao apresentar uma definição ampla e abrangente de pesquisa envolvendo seres humanos (Resolução CNS n. ${ }^{\circ}$ 510, 2016).

Em consonância ao disposto nas Resoluções CNS n. ${ }^{\circ}$ 196/1996 e n 466/2012, a Resolução CNS n. ${ }^{\circ}$ 510/2016 mantém a compulsoriedade do prévio consentimento livre e esclarecido (CLE) do participante para realização de pesquisas. Contudo, a citada normativa ética possibilita uma adaptação da obtenção do consentimento à realidade vivenciada por pesquisadores da CHS, ao estabelecer a possibilidade do registro da anuência dos participantes em diferentes meios, formatos ou mídias. (Guerriero, 2016; Mainardes, 2017).

\section{Resultados: o Conceito de Risco nas Normativas Nacionais que Versam Sobre Ética em Pesquisa 4.1 Resolução CNS no $1 / 1988$}

Em consonância com o estabelecido nas diretrizes e regulamentos internacionais que versam acerca da avalição ética da prática científica que se realiza com seres humanos, a Resolução CNS n ${ }^{\circ}$ 1/1988 prescreve que em todo estudo com seres humanos os benefícios devem prevalecer em relação aos riscos mensurados. Isto posto, a citada diretriz ética conceitua risco da pesquisa como "a probabilidade de que o indivíduo sofra algum dano como consequência (sic) imediata ou tardia do estudo" (Resolução CNS nº 1, 1988, p. 1).

É importante acentuar que o conceito de risco presente na Resolução CNS n ${ }^{\circ} 1 / 1988$, portanto, caracteriza a probabilidade de um dano ao participante ocasionado pela realização da pesquisa. Também se observa que o dano ao participante ocorrer durante a participação da pesquisa (dano imediato) ou após o termino da pesquisa (dano tardio) (Resolução CNS no 1, 1988).

A partir da conceituação de risco com a probabilidade de dano imediato ou tardio ocasionado ao participante, a Resolução CNS $n^{\circ}$ 1/1988 estipula uma classificação da pesquisa em saúde com seres humanos, de acordo como a 
possibilidade dos riscos inerentes a sua realização. A normativa ética nacional, portanto, define três categorias de pesquisa conforme a probabilidade de risco, a saber: I. pesquisa sem risco; II. pesquisa com risco mínimo; e III. pesquisa com o risco maior que o mínimo.

A pesquisa sem risco é definida pela utilização de métodos ou técnicas de pesquisa que não ocasionem alteração na integridade fisiológica ou psicossocial dos participantes (Resolução CNS $n^{\circ}$ 1, 1988). Podem ser categorizadas como pesquisa do tipo sem risco, os estudos realizados por meio de questionários ou entrevistas e as pesquisas em prontuários que não possibilitem a identificação dos sujeitos. intervenção ou modificação intencional nas variáveis fisiológicas ou psicológicas e sociais dos indivíduos que participam no estudo (Resolução CNS nº 1, 1988).

A pesquisa com risco mínimo categoriza os estudos que analisem dados individuais e/ou pessoais registrados durante a realização de procedimentos, exames ou tratamentos (Resolução CNS nº 1, 1988). Como exemplo dessa categoria de pesquisa, pode-se mencionar as pesquisas realizadas com dados de eletrocardiograma, hemograma, obtenção de placenta, dentro outros (Resolução CNS nº 1, 1988).

A pesquisa com o risco maior que o mínimo, por fim, engloba o estudo que a sua realização tem a probabilidade de causar danos ou implicações significativas aos participantes ou à coletividade (Resolução CNS nº 1, 1988). Caracteriza-se como pesquisa com o risco maior que o mínimo, por exemplo, estudos radiológicos e com micro-ondas, dentre outros fundamentados em técnicas ou procedimentos evasivos (Resolução CNS nº 1, 1988).

Em resultância do seu direcionamento para a regulamentação ética das Ciências da Saúde, notadamente, de estudos farmacêuticos, constata-se que a Resolução CNS n $1 / 1988$ categoriza as pesquisas com seres humanos através de uma noção biomédica de risco e, consequentemente, das possíveis implicações ou danos, principalmente, à integridade física do participante. À vista disso, destaca-se que a classificação das pesquisas em sem riscos, com risco mínimo ou com o risco maior que o mínimo fundamenta a verificação ética realizada pelos CEs e CSBs.

A Resolução CNS n ${ }^{\circ}$ 1/1988 estatui que, mesmo em caso de estudos sem riscos, é obrigação do pesquisador responsável suspender imediatamente a realização da pesquisa caso constate a ocorrência de algum dano ou risco à saúde do participante que não foi previsto. Também fica estabelecido que a instituição de saúde responsável pela pesquisa deve fornecer, obrigatoriamente, assistência ao participante, sem qualquer possível prejuízo para o requerimento de indenização.

Ao dialogar com as diretrizes éticas internacionais, a Resolução CNS nº 1/1988 define que toda participação em pesquisa na área de saúde deve ser precedida pelo consentimento pós-informado, de livre arbítrio e sem qualquer tipo de coação dos sujeitos. Sendo assim, pressupõe que o pesquisador irá informar o indivíduo objeto da pesquisa, de maneira completa e acessível, a sobre "[...] a natureza dos procedimentos e riscos a que se submeterá" (Resolução CNS no 1, 1988, p. $3)$.

Ademais, a mencionada resolução versa que o consentimento Pós-Informação indivíduo objeto da pesquisa ou de seu representante legal deve ser registrado por escrito. O Consentimento Pós-Informação, portanto, é definido como um documento por escrito elaborado pelo pesquisador, mas analisado pelo CE da instituição e que deve será assinado pelo pesquisador e pelo participante ou pelo seu representante legal. Vale pontuar que o documento deve ser assinado em duas vias, sendo uma entregue ao pesquisador e outra ao participante ou ao seu representante legal. Além disso, caso o participante não saiba ou possa assinar, o Consentimento Pós-Informação será registrado por meio de assinatura datiloscópica.

A Resolução CNS n ${ }^{\circ}$ /1988 coloca algumas exceções para a utilização do Consentimento Pós-Informação em estudos de risco mínimo ou sem risco. Nos estudo classificados como de risco mínimo, o pesquisador pode solicitar ao CE que o Consentimento Pós-Informação não seja obtido por escrito. Caso o estudo seja classificado como sem risco, o pesquisador pode requerer a dispensa da obrigatoriedade registro do Consentimento Pós- Informação junto ao CE (Resolução CNS $n^{\circ} 1$, 1988). 
Em pesquisa realizada com menores ou indivíduos que não possam emitir o Consentimento Pós-Informação de maneira consciente, os riscos devem ser justificados pela relevância dos possíveis benefícios (Resolução CNS nº 1, 1988). De maneira complementar, quando a pesquisa tiver alguma possibilidade de risco mínimo e não trará benefício, a diretriz em análise atrela sua realização à possibilidade de o participante ter condições de suportar bem o procedimento ou os resultados proporcionarem possibilidade melhoria a outros indivíduos (Resolução CNS nº 1, 1988).

Todavia, caso a pesquisa realizada com menores ou indivíduos que não possam emitir o Consentimento PósInformação de maneira consciente possua riscos maiores que o mínimo, a resolução pressupõe sua admissibilidade à possibilidade de geração de conhecimento para a compreensão, prevenção ou alivio de problemas grave que afete o participante. Nesses casos, o CE deve realizar o constante acompanhamento para verificar a possibilidade aumento dos riscos e, se for o caso, solicitar a interrupção da pesquisa (Resolução CNS nº 1, 1988).

A respeito da pesquisa em saúde como risco maior que o mínimo que preveja a participação de mulheres férteis, a Resolução CNS no 1/1988 estatui a obrigatoriedade de as participantes não estarem grávidas. Além disso, é responsabilidade do pesquisador orientar as participantes sobre a importância de não engravidarem durante a realização do estudo (Resolução CNS n $\left.{ }^{\circ} 1,1988\right)$.

Os estudos com mulheres grávidas têm que possibilitar algum benefício terapêutico, mas não devem "ter risco maior que o mínimo para a mulher, o embrião ou o feto" (Resolução CNS n 1, 1988, p. 7). Se a pesquisa objetiva um procedimento não relacionado à gravidez, este não pode expor o embrião ou o feto a probabilidade de um risco maior que o mínimo, excetuando-se os casos que a realização do procedimento é necessária para salvar a vida da gestante (Resolução CNS $\mathrm{n}^{\circ} 1$, 1988).

O estudo com mulheres grávidas que possibilita benefícios terapêuticos relacionados à gravidez tem sua realização atrelada à melhoria da saúde da gestante e à ocorrência de riscos mínimos ao embrião/feto ou ao aumento da "[...] viabilidade do feto com o risco mínimo para a grávida" (Resolução CNS n 1 1, 1988, p. 7). Se a pesquisa for realizada no decorrer da lactação, sua realização pressupõe a inexistência de riscos para o lactante ou a impossibilidade da puérpera fornecem ou realizar a amamentação. Adicionalmente, observa-se que os estudos com recém-nascidos só podem ser realizados caso não gerem qualquer tipo de risco (Resolução CNS nº 1, 1988).

Em caso de pesquisa farmacológica que envolva o tratamento de urgências, caso o Termo de Consentimento PôsInformação (TCPI) não possa ser assinado pelo participante ou responsável legal ou familiar próximo e a não utilização da droga coloque em risco a vida do participante, a Resolução CNS n ${ }^{\circ}$ 1/1988 autoriza a realização da pesquisa sem o registro do Consentimento Pôs-Informação.

O pesquisador principal de estudos com microrganismos patogênicos ou material biológicos que possa contê-los devem definir os procedimentos de segurança, a partir do grau de risco de infecção que apresentam os microrganismos a serem utilizados (Resolução CNS n 1, 1988). Sendo assim, a Resolução CNS nº 01/1988 orienta que os microrganismos devem ser classificados em quatro grupos e conforme a possibilidade de risco de contaminação ou infecção para o indivíduo ou para a coletividade.

Adicionalmente, a Resolução CNS $\mathrm{n}^{\circ}$ 01/1988 regulamenta que o pesquisador principal de estudos com microrganismos patogênicos ou material biológicos que possa contê-los deve mensurar os riscos reais e potenciais e comunicar a equipe executora e os participantes sobre estes (Resolução CNS nº 1, 1988). Por conseguinte, os CSBs devem fazer a avaliação constante do manuseio dos microrganismos patogênicos ou do material biológicos para identificar possíveis práticas que possam ocasionar riscos relacionados a infecção ou contaminação biológica (Resolução CNS nº 1, 1988).

A realização de estudos com isótopos radioativos; dispositivos e geradores de radiações ionizantes e eletromagnéticas pressupõe a realização de ações de segurança radiológica e física aos possíveis riscos à saúde de todos os envolvidos 
na execução da pesquisa (Resolução CNS no 1, 1988). A resolução em questão também ressalta que gestante ou mulheres lactantes não devem trabalhar em locais que exista a possibilita de risco radioativo (Resolução CNS $\mathrm{n}^{\circ}$ 1, 1988). Ainda sobre pesquisa com riscos relacionados à exposição a radiações ionizantes, a supracitada resolução justifica sua realização à impossibilidade de coleta de informações com menor possibilidade risco por meio de outras técnicas.

Por conseguinte, a Resolução CNS nº 01/1988 relaciona a implantação do CBS em instituições de saúde credenciada pelo CNS à realização de pesquisa que representem risco biológico ou radioativo para a saúde, bem como sobreleva a importância da revisão dos riscos para a emitir parecer sobre os aspectos éticos das pesquisas propostas aos CEs (Resolução CNS n $\left.{ }^{\circ} 1,1988\right)$.

\subsection{Resolução CNS nº 196/1996}

A Resolução CNS nº 196/1996 possui uma análise de risco mais ampla que a Resolução CNS nº 1/1988, pois, diferentemente da normativa anterior, busca regulamentar o exame ético de pesquisa com seres humanos independente da área de conhecimento ou da metodologia prevista. Sendo assim, a citada diretriz nacional conceitua o risco da pesquisa como a "[...] possibilidade de danos à dimensão física, psíquica, moral, intelectual, social, cultural ou espiritual do ser humano, em qualquer fase de uma pesquisa e dela decorrente" (Resolução CNS n 196, 1996, p.1).

O dano decorrente do desenvolvimento de uma pesquisa, como na Resolução CNS n $1 / 1988$, pode ser imediato ou tardio, direto ou indireto e afetar o individuou e/ou a coletividade. Além disto, a Resolução CNS nº 196/1996 mantém a compulsoriedade da obtenção da anuência do participante ou de seu representante legal, após o esclarecimento completo e detalhado sobre a natureza da pesquisa.

Com a intenção de tornar o consentimento dos sujeitos da pesquisa livre e esclarecido, a Resolução CNS n 196/1996 exige a utilização de linguagem acessível e adequada aos participantes, detalhamento da justificativa, dos objetivos e da metodologia, definição das formas de acompanhamento, garantia de esclarecimento em qualquer etapa, liberdade de o sujeitos recusarem participar do estudo em qualquer momento, garantia de sigilo e privacidade, definição das formas de ressarcimento e indenização, bem como a definição de todos os riscos e os benefícios possíveis.

Ademais, a referida resolução salienta que o consentimento deverá ser registrado por escrito, por meio da utilização do Termo de Consentimento Livre e Esclarecido (TCLE), documento que será previamente analisado e aprovado por um CEP. O TCLE, portanto, deverá ser redigido pelo pesquisador e assinado em duas vias por este e pelo participante ou pelo seu responsável (Resolução CNS nº 196, 1996).

Adicionalmente ao consentimento livre e esclarecido (CLE), ao compromisso em evitar os danos mensuráveis e à relevância de cunho social e coletivo, a Resolução CNS nº 196,/1996 vincula a eticidade da pesquisa à elucubração dos riscos e benefícios, assim como ao comprometimento em promover os maiores benefícios por meio da exposição os mínimos riscos (preponderância de benefícios sobre riscos). Portanto, no procedimento científico com participante deve prevalecer os benefícios esperados sobre riscos e custos (Resolução CNS nº 196, 1996).

Em relação aos estudos científicos que tenham mulheres em idade fértil ou gestantes como sujeitos de pesquisa, a Resolução CNS nº 196/1996 relaciona a delimitação dos riscos e benefícios à possibilidade de danos ou interferência na fertilidade, na gravidez, lactação ou na saúde do feto/embrião/recém-nascido.

A Resolução CNS nº 196/1996 considera que a/o pesquisa/estudo com participantes tem a probabilidade de ocasionar riscos aos indivíduos e/ou à coletividade. Isto posto, apesar da possibilidade de riscos, a normativa em questão relaciona a sanção das pesquisas à possibilidade de benefício que justifique o risco, benéficos igual ou maior que outras formar de tratamento ou pesquisa e/ou à possibilidade resultados que contribuam para o bem-estar dos participantes (Resolução CNS nº 196, 1996). 
Todavia, apesar de aprovado pelos CEPs, o estudo deve ser compulsória e imediatamente interrompido, se o pesquisador observar a ocorrência de algum risco não mensurado no TCLE ou se constatar a existência de metodologia ou procedimento que possibilite os mesmos resultados com menores riscos (Resolução CNS n 196, 1996). Em contraponto ao estabelecido pela Resolução CNS N 1/1988, a Resolução CNS nº 196/1996 vincula a responsabilidade pela assistência dos indivíduos, em caso de riscos oriundos da realização do estudo, ao pesquisador principal, ao patrocinador do estudo e a instituição proponente.

No tocante aos riscos, o protocolo de pesquisa, conjunto de documentos submetidos ao Sistema CEP/CONEP, deve conter a descrição dos riscos e benefícios, a avaliação da possibilidade de ocorrência e a mensuração da gravidade de cada risco (Resolução CNS n 196, 1996). O pesquisador também deve apresentar, no momento da submissão do protocolo de pesquisa, as ações e estratégicas para minimização de todos os riscos esperados (Resolução CNS n ${ }^{196}, 1996$ ).

A respeito de estudos com menores ou indivíduos impossibilitados de emitir o CLE ou com diminuição na capacidade de consentimento, a Resolução CNS n 196/1996 atrela a realização da pesquisa à emissão do CLE dos representantes legais dos referidos participantes, sem qualquer "[...] suspensão do direito de informação do indivíduo, no limite de sua capacidade" (Resolução CNS n ${ }^{\circ}$ 196, 1996, p. 4). Ademais, a normativa ética em questão exige que a proposta de pesquisa submetida ao CEP apresente justificativa fundamentada para a escolha dos participantes (Resolução CNS ${ }^{\circ} 196$, 1996).

\subsection{Resolução CNS nº 466/2012}

A Resolução CNS no 466/2012 mantém a concepção ampla de risco como um dano às dimensões que compõem a integridade do indivíduo ocasionado, direta ou indiretamente, pela execução do estudo ou procedimento. Também preserva a concepção de CLE, salientando a importância dessa etapa ser livre de possíveis vícios, bem como a forma de registro por meio do TCLE (Cardoso, Gomes, \& Rocha, 2018; Thomasi, 2016).

Como novidade, a Resolução CNS n ${ }^{\circ}$ 466/2012 estatui a necessidade de obtenção da anuência do participante criança, adolescente ou legalmente incapaz como assentimento livre e esclarecido (ALE). De maneira complementar, o documento esclarece que esse processo deve ser adequado e respeitar as peculiaridades dos participantes, ser registrado por meio do Termo de Assentimento e, entre outras informações relativas à natureza da pesquisa, detalhar os riscos possíveis (Resolução CNS n $\left.{ }^{\circ} 466,2012\right)$.

Nos estudos que a utilização do TCLE ou do Termo de Assentimento para o registro do consentimento/assentimento dos participantes for inviável, pois pode ocasionar algum risco ou quebra de confiança na relação pesquisador-participante, pode-se solicitar ao Sistema CEP/CONEP a dispensa do registro da anuência por escrito (Resolução CNS n 466, 2012).

No tocante à eticidade da pesquisa com participante, a Resolução CNS n ${ }^{\circ}$ 466/2012 reafirma a necessidade da ponderação entre os riscos e os benefícios. Todavia, também assegura a importância da prevalência dos benefícios em relação aos riscos e aos desconfortos (Resolução CNS nº 466, 2012).

Acerca dos estudos com mulheres em idade fértil ou gestantes, conserva a necessidade da avaliação dos riscos e dos benefícios levar em considerando os impactos à fertilidade e/ou à integridade da gestante e do feto/embrião/recém-nascido, como também ao parto, ao puerpério e ao processo de lactação (Resolução CNS n 466, 2012). Como adicional, a normativa ética nacional em análise exige que as participantes em idade fértil manifestem, de forma prévia, a isenção dos riscos de gravidez.

A Resolução CNS n 466/2012 menciona que a utilização de placebos deve ser justificada e analisada de maneira criteriosa, pois os benefícios e os risco decorrentes da utilização de novos métodos terapêuticos devem ser analisados e comparados com os métodos atuais e vigentes. Contudo, a normativa em análise salienta que a solicitação de prévia 
justificação "[...] não exclui o uso de placebo ou nenhum tratamento em estudos nos quais não existam métodos provados de profilaxia, diagnóstico ou tratamento" (Resolução CNS nº 466, 2012, p. 4).

A resolução em questão mantém o pressuposto de que a pesquisa com seres humanos envolve algum risco que pode variar em tipos e/ou gradações (Resolução CNS n 466, 2012). Contudo, estabelece que quanto maiores e evidentes os riscos, maiores devem ser os cuidados para minimizá-los e a proteção oferecida pelo Sistema CEP/CONEP aos participantes (Resolução CNS nº 466, 2012).

A análise de risco é compreendida como um componente/etapa fundamental da revisão da eticidade da pesquisa com participantes e o monitoramento dos riscos deve ser executado pelo Sistema CEP/CONEP. Ademais, infere-se que a realização de estudos com participantes continua atrelada à justificativa dos riscos pelos benefícios (Resolução CNS no 466 , 2012). Além disso, a Resolução CNS nº 466/2012 reafirma que, em caso de risco ou dano não previsto no TCLE, o estudo deve ser adequado ou suspenso.

Dentre as pesquisas de áreas temáticas especiais analisadas pela CONEP, depreende-se a menção os projetos de pesquisa com organismos que representem elevado risco coletivo². Ainda é definida como atribuição da CONEP o monitoramento dos riscos de estudos que exigem uma maior proteção dos participantes.

Em relação às atribuições dos CEPs, a Resolução CNS nº 466/2012 pontua, dentre outras, o acompanhamento dos projetos aprovados, conforme os riscos inerentes à realização de cada estudo. A seguir, institui que a classificação e a mensuração dos riscos nas várias metodologias utilizadas nos estudos com participantes serão detalhadas em uma resolução específica. Cabe pontuar que somente a Resolução CNS n ${ }^{\circ}$ 01/1988 versa sobre os tipos de pesquisa de acordo com a gradação dos riscos.

\subsection{Resolução CNS N 510/2016}

A Resolução CNS n 510/2016 faz referência a natureza específica dos riscos nas pesquisas com participantes na CHS, frisando a inexistência de intervenção física no corpo humano. Para mais, estabelece seu direcionamento para estudos e CHS que ocasionem riscos maiores que os presentes no cotidiano dos participantes. Cabe pontuar que a Resolução CNS $n^{\circ}$ 510/2016 conceitua a pesquisa com participantes nas CHS como:

[...] aquelas que se voltam para o conhecimento, compreensão das condições, existência, vivência e saberes das pessoas e dos grupos, em suas relações sociais, institucionais, seus valores culturais, suas ordenações históricas e políticas e suas formas de subjetividade e comunicação, de forma direta ou indireta, incluindo as modalidades de pesquisa que envolvam intervenção (Resolução CNS no 510, 2019, p. 4).

Em decorrência do seu caráter complementar, a Resolução CNS nº 510/2016 conserva as conceituações de risco da pesquisa, de ALE e CLE. Todavia, faz uma distinção entre dano material e dano imaterial, assim como separa o esclarecimento do participante do registro do consentimento (Resolução CNS nº 510, 2016).

Conforme mencionado anteriormente, a normativa em análise estatui a possibilidade de registro do consentimento em diferentes meios ou mídias, porem relaciona a escolha do meio de registro à análise do o grau de risco envolvido para os

\footnotetext{
2 Em resumo, a Resolução CNS No 466/2012 estabelece, em sua seção VII, como atribuição exclusiva da CONEP analisar pesquisas das seguintes áreas temáticas especiais: genética humana; reprodução assistida; manipulação de gametas, pré-embriões, embriões e feto; medicina fetal; vacinas novas (fases I, II e III) ou não registradas no País (ainda que fase IV); equipamentos, insumos e dispositivos para a saúde, novos ou não registrados no País; novos procedimentos ainda não consagrados na literatura; estudos com populações indígenas; projetos que envolvam aspectos de biossegurança: projetos de pesquisa que envolvam organismos geneticamente modificados (OGM), células tronco embrionárias e organismos que representam alto risco coletivo, pesquisas coordenadas no exterior ou com participação estrangeira e pesquisas que envolvam remessa de material biológico humano para o exterior; projetos que, a critério do CEP, sejam julgados merecedores de análise pela CONEP; e protocolos de constituição e funcionamento de biobancos.
} 
participantes. Caso, em decorrência de riscos aos participantes ou ao pesquisador, o registro de CLE ou do ALE for inviável, o pesquisador pode solicitar a sua dispensa ao sistema CEP/CONEP (Resolução CNS nº 510, 2016).

Quando o estudo se trata de uma pesquisa do tipo encoberta, aquela que é executada sem o prévio esclarecimento do participante a respeito dos procedimentos e objetivos e, consequentemente, sem o seu consentimento, fica estabelecido que o pesquisador deve justificar ao Sistema CEP/CONEP como o repasse de informações aos participantes alteraria o resultado do estudo (Resolução CNS n 510, 2016). De maneira complementar, a normativa ética em análise orienta que, se possível, o consentimento dos participantes deve ser realizado após a execução da pesquisa do tipo encoberta.

A Resolução CNS nº 510/2016 define como um dos aspectos da eticidade na pesquisa em CHS, a responsabilidade de pesquisadores e participantes não criarem, manterem ou ampliarem os eventos que propiciem riscos ou a vulnerabilidade no contexto individual ou coletivo. Em relação aos riscos nos projetos de pesquisa, observa-se a vinculação da definição e da mensuração dos graus dos riscos à análise dos possíveis danos que podem ser ocasionados pelos procedimentos metodológicos empregados na realização da pesquisa (Resolução CNS $n^{\circ} 510,2016$ ). Desse modo, orienta-se que o pesquisador esteja constantemente atento à ocorrência de riscos e realize as ações e medidas necessárias para a minimização destes, principalmente, em estudos com crianças, adolescentes ou indivíduos com limitação de autonomia (Resolução CNS nº 510, 2016).

Na Resolução CNS n 510/2016, verifica-se que os riscos descritos no protocolo de pesquisa serão classificados em baixo, moderado ou elevado, considerando-se as especificidades de cada projeto, bem como a conceituação descrita em normativa específica (Duarte, 2017; Silva \& Portela, 2017). A análise dos protocolos das CHS, portanto, será condicionado pela adequação entre a classificação dos riscos e os níveis de precaução e proteção do participante (Resolução CNS ${ }^{\circ} 510$, 2016).

Isto posto, impõe-se que a análise da eticidade dos projetos deve considerar os riscos e as medidas para minimizá-los. De modo consequente, prescreve-se que a revisão ética deve ser direcionada para os aspetos metodológicos que possam acarretar riscos aos participantes (Resolução CNS no 510, 2016). O documento ético em questão, em seguida, define como responsabilidade exclusiva do pesquisador apresentar a mensuração e tipificação dos riscos inerentes à realização da pesquisa no protocolo submetido ao Sistema CEP/CONEP (Resolução CNS nº 510, 2016).

\subsection{Breve discussão a respeito dos riscos nas normativas brasileiras sobre ética em pesquisa}

Ante as discussões expostas nas seções anteriores, constata-se a centralidade do conceito de risco para o processo de apreciação ética dos estudos com seres humanos. Ademais, observou-se que os debates a respeito dos aspectos éticos da prática científica com seres humanos têm como pressuposto que a pesquisa não pode ocasionar mais riscos que benefícios aos participantes. A análise dos riscos, portanto, é a etapa fundamental para os CEPs e a CONEP aprovarem eticamente ou não uma proposta de pesquisa.

Em todas as resoluções analisadas, o conceito de risco é significado ou conceituado como a probabilidade de ocorrência de algum dano direto ou indireto e imediato ou tardio ao participante. Contudo, enquanto a Resolução CNS ${ }^{\circ}$ 1/1988 possui uma concepção biomédica de risco, pautada na probabilidade de danos físicos aos participantes, as Resoluções CNS n 196/1996, nº 466/2012 e nº 510/2016 contêm uma definição desse conceito mais ampla e que retrata a exequibilidade de danos às diversas dimensões que compõem a integridade do participante.

Com base no preconizado pelas diretrizes internacionais sobre ética em pesquisa, as resoluções em análise determinam que todos os estudos com seres humanos devem, obrigatoriamente, definir as ações e estratégias que objetivem a minimização dos possíveis riscos decorrentes da sua realização. À vista disso, é necessário frisar que toda pesquisa com seres humanos passará por um prévio exame ético dos riscos e benefícios (Araújo, 2003; Lemos t al, 2019). 
Isto posto, pode-se inferir que o risco, nas resoluções nacionais sobre a pesquisa envolvendo seres humanos, possui uma conceituação multidimensional que retrata a possibilidade de danos ao participante (Peixto, 2016; Pessalacia \& Oliveira, 2011). Em consequência, a verificação ética dos estudos com seres humanos pressupõe a reflexão acerca dos riscos e benefícios esperados (Guilhem \& Diniz, 2017). Nessa perspectiva, Peixoto (2016) argumenta que a noção de risco estabelecida pelas normativas nacionais e internacionais sobre ética em pesquisa caracteriza a:

[...] possibilidade de danos à dimensão física, psíquica, moral, intelectual, social, cultural do ser humano, em qualquer etapa da pesquisa e dela decorrente. Ainda que existam diversos tipos e níveis de risco distintos, um parâmetro básico de avaliação a ser levado em conta pelos pesquisadores estabelece que o risco não deve ser maior do que aquele ao qual a pessoa está exposta no seu dia a dia. Para além desse ponto, deve-se estar atento às consequências da pesquisa e formas de minimização de risco precisam ser adotadas de modo a garantir o bem-estar dos participantes (Peixoto, 2016, p. 330).

Portanto, o Sistema CEP/CONEP tem a responsabilidade de examinar se os benefícios são mais relevantes que os riscos, pois as resoluções brasileiras sobre ética em pesquisa determinam que serão aprovadas unicamente as pesquisas que possuam a justificação dos riscos pelos benefícios esperados ou a possibilidade de produção de conhecimento que promova o aumento do bem-estar dos participantes. Dialogando com os documentos e regulamentos internacionais, as resoluções brasileiras, desse modo, revalidam a compulsoriedade da realização de estudos ser atrelada à existência de riscos menores que os possíveis benefícios. As diretrizes brasileiras também sublinham que a checagem dos riscos deve preconizar, em adicional, as ações voltadas para a sua minimização.

Observa-se que as resoluções nacionais reafirmam a compulsoriedade do prévio CLE do participante para a execução da pesquisa. Nesse sentido, infere-se que as Resoluções CNS n 1/1988, № 196/1996 e n 466/2012 mantém a necessidade do registro por escrito do CLE através do TCLE. Todavia, a Resolução CNS nº 510/2016, ao reconhecer as especificidades da pesquisa nas CHS, possibilita o registro do CLE em variados formatos ou mídias (Duarte, 2017; Mainardes, 2017).

O surgimento do sistema brasileiro de regulamentação ética parte do pressuposto, reconhecido por todas as diretrizes éticas internacionais, de que toda pesquisa que envolva seres humanos inflige riscos que podem variar em grau, tipo ou intensidade (Guilhem, \& Diniz, 2017; Mainardes, 2017; Sarti, 2015). No entanto, somente a Resolução CNS nº $1 / 1988$ estabelece critérios para a mensuração das pesquisas, conforme os níveis ou gradações dos riscos.

Tanto as Resoluções no 196/1996 e nº 466/2012 como também a Resolução CNS n. ${ }^{\circ}$ 510/2016 fundamentam, a partir de uma tendência biomédica, a atuação dos CEPs e da CONEP na verificação hierarquização dos riscos, isto é, as normativas mencionam riscos mínimos, elevados ou máximos, porém, excetuando-se a Resolução CNS nº $1 / 1988$, não determinam os critérios que os pesquisadores e as instâncias colegiadas devem empregar para classificar os riscos inerentes à realização dos estudos.

A questão relacionada à hierarquização dos riscos presente na Resolução CNS no 510/2016 é, constantemente, debatida e criticada, pois a multiplicidade de abordagens metodológicas e as especificidades da participação em estudos das CHS ocasiona dificuldades para uma classificação dos riscos em mínimo, baixo, moderado ou elevado (Amaral Filho, 2017; Guerriero, 2016; Mainardes, 2017; Sarti, 2015). Nessa perspectiva, Amaral Filho (2017) argumenta que a hierarquização dos ricos é uma temática que a referida resolução complementar poderia ter avançado, pois não é possível mensurar, de maneira abrangente e prévia, os níveis de riscos em pesquisas com participantes nas CHS.

Por fim, cabe mencionar que as Resoluções CNS nº 466/2012 e no 510/2016 preveem que a classificação e a mensuração dos riscos nos estudos com participantes serão detalhadas e regulamentadas em uma resolução específica, elaborada e publicada pelo CNS (Duarte, 2017; Mainardes, 2017; Silva \& Portela, 2017; Witiuk, França, Krüger, \& Guebert, 
2018). Contudo, constata-se que, até o presente momento, essa riscos resolução não foi publicada e o processo de hierarquização dos possíveis é fundamentado por critérios próprios e estabelecidos pelos pesquisadores e/ou pelos CEPs.

\section{Conclusão}

As discussões apresentadas no presente estudo evidenciaram a importância/centralidade do conceito de risco para o processo de apreciação ética realizado pelo Sistema CEP/CONEP. Para a primeira resolução nacional sobre ética em pesquisa, este conceito é relacionado à probabilidade risco físico (Resolução CNS no 1, 1988). Em decorrência da regulamentação de toda pesquisa envolvendo seres humanos, as resoluções posteriores conceituam o conceito de risco como a probabilidade de danos às diversas dimensões que compõem a integridade do ser humano (Resolução CNS nº 196, 1996; Resolução CNS nº 466, 2012; Resolução CNS nº 510/2016).

Conclui-se que a exigência do consentimento prévio dos participantes para a realização de qualquer pesquisa com seres humanos é fundamental para que o indivíduo tenha conhecimento dos riscos aos quais será exposto e, consequentemente, possa anuir em participar do estudo de maneira livre e esclarecida (Resolução CNS nº 1, 1988; Resolução CNS nº 196, 1996; Resolução CNS no 466, 2012; Resolução CNS nº 510/2016). Entretanto, também se compreende que a classificação dos riscos é imprescindível para o processo de consentimento e para apreciação ética das pesquisas em si (Resolução CNS nº 1, 1988; Resolução CNS nº 196, 1996; Resolução CNS n 466, 2012; Resolução CNS nº 510/2016).

Entende-se que o presente trabalho disponibiliza uma apresentação geral da utilização do conceito de risco nas resoluções brasileiras sobre ética na pesquisa. Porém, observou-se que as resoluções vigentes, Resoluções CNS n 466/2012 e $n^{\circ} 510 / 2016$, estabelecem uma classificação dos riscos em níveis. Nesse sentido, salienta-se que as mencionadas resoluções condicionam o processo de tramitação dos protocolos à gradação dos riscos mensurados. No entanto, constata-se que as Resoluções CNS n 466/2012 e n 510/2016 não definem os critérios que orientariam a tipificação e a gradação de riscos na pesquisa com seres humanos. Por conseguinte, ressalta-se que as duas resoluções vigentes fazem referência à publicação de uma diretriz ética do CNS que versará a respeito dos critérios para mensuração dos níveis de riscos, porém observa-se que essa normativa ainda não foi elaborada.

Por fim, sugere-se que as pesquisas posteriores abordem e discutam os critérios que fundamentam a classificação/hierarquização dos possíveis riscos realizada tanto pelos pesquisadores como pelos colegiados dos CEPs. Apontase também que a publicação da resolução sobre a mensuração dos riscos possibilitará a realização de estudos complementares sobre a implicação da execução de determinadas pesquisas para a integridade dos participantes.

\section{Referências}

Araújo, L. Z. S. de. (2003). Aspectos éticos da pesquisa científica. Pesquisa Odontológica Brasileira, 17(1), 57-63.

Amaral Filho, F. S. (2017). Ética e pesquisa nas Ciências Humanas e Sociais: um caso a ser pensado. Práxis Educativa (Brasil), 12(1), $257-266$.

Amorim, K. P. C. (2019). Ética em pesquisa no sistema CEP-CONEP brasileiro: reflexões necessárias. Ciência \& Saúde Coletiva, $24,1033-1040$.

Barros, E., \& Barros, H. M. (2009). Medicamentos na prática clínica. Artmed Editora.

Bento, L. A. (2011). Bioética e pesquisa em seres humanos. Editora Paulinas.

Bernstein, P. L. (1997). Desafio aos deuses: a fascinante história do risco. Editora Campus.

Capron, A.M. (1989). Human experimentation. In R.M. Veatch (Ed.). Medical ethics. Jones \& Bartlett, 125-172.

Cardano, M. (2017). Manual de pesquisa qualitativa: uma contribuição da teoria da argumentação, Editora Vozes.

Cardoso, P. K. B., Gomes, A. V., \& Rocha, F. C. V. (2018). Ética E Bioética Em Pesquisa: Conhecimento De Acadêmicos Do Curso De Enfermagem. Revista Uningá, 55(4), 209-219. 
Cechinel, A., Fontana, S. A. P., Della, K. G. P., Pereira, A. S., \& Prado, S. S. (2016). Estudo/análise documental: uma revisão teórica e metodológica. Revista Criar Educação, 5(1).

Damodaran, A. (2008). Gestão estratégica do risco. Bookman Editora.

Declaração de Helsinque (2013). Princípios éticos para pesquisa médica envolvendo seres humanos.

Recuperado em 25 de abril de 2021 de: 〈http://www.amb.org.br/_arquivos/_downloads/491535001395167888_DoHBrazilianPortugueseVersionRev.pdf>.

Duarte, L. F. D. (2017). Cronologia da luta pela regulação específica para as Ciências Humanas e Sociais da avaliação da ética em pesquisa no Brasil. Práxis Educativa (Brasil), 12(1), 267-286.

Ferreira, A. B. D. H. (2010). Dicionário Aurélio da língua portuguesaEditora Positivo.

Gil, A. C. (2008). Métodos e técnicas de pesquisa social. Editora Atlas SA.

Guerriero, I. C. Z. (2016). A resolução 510/16: diretrizes éticas para pesquisas em Ciências Humanas e Sociais. Cadernos Brasileiros de Terapia Ocupacional, 24(3)

Guilhem, D., \& Diniz, D. (2017). O que é ética em pesquisa. Editora Brasiliense.

Kipper, D. J. (2010). Breve história da ética em pesquisa. Revista da AMRIGS, 54(2), 224-228.

Kottow, M. (2008). História da ética em pesquisa com seres humanos. Revista Eletrônica de Comunicação, Informação e Inovação em Saúde, 2, 7-18.

Labronici, L. M., Raimondo, M. L., Trigueiro, T. H., Raimondo-Ferraz, M. I., \& Ramos, C. C. (2012). Caracterização de protocolos de pesquisa apreciados por um comitê de ética. Ciência, Cuidado e Saúde, 11(2), 284-293.

La Mendola, S. (2005). O sentido do risco. Tempo social, 17(2), 59-91.

Lemos, P. B. S., Aquino, F. J. A., Silva, S. A., Jucá, S. C. S., \& Silva, F. E. M. (2019). Análise do perfil acadêmico e profissional dos membros de comitês de ética em pesquisa implantados em instituições da rede federal de educação profissional, científica e tecnológica da região nordeste do Brasil. Research, Society and Development, 8(9), e23891275-e23891275.

Lordello, S. R., \& Silva, I. M. D. (2017). Resolução nº 510/2016 do Conselho Nacional de Saúde: um panorama geral. Revista da SPAGESP, 18, 06-15

Mainardes, J. (2017). A ética na pesquisa em educação: panorama e desafios pós-Resolução CNS nº 510/2016. Educação, 40(2), 160-173.

Minayo, M. C. S. (2002). Ciência, Técnica e Arte: o desafio da pesquisa social. In: Minayo, M.C. S. (ORG.). Pesquisa Social: Teoria, Método e criatividade. Vozes, 09-29.

Moura, J. M. B., Silva, R. H., Silva, N. A., Sousa, D. C. P., \& Albuquerque, U. P. (2021). Preparação da pesquisa qualitativa. In Albuquerque, U. P., Cunha, L. V. F. C., Lucena, R. F. P., Alves, R. R. N. (Editores). Métodos de pesquisa qualitativa para etnobiologia. Nupeea, 45-62.

Paiva, P. A., Costa, S. de M., Dias, O. V., Lopes, V. S. V. B. V., Souto, D. G. B., \& Silva, D. L. da. (2015). Experiência do comitê de ética em pesquisa de uma universidade pública de Minas Gerais, Brasil. Revista Bioética, 23(1), 169-177.

Peixoto, P. (2017). Ética e regulação da pesquisa nas Ciências Sociais na sociedade do consentimento. Educação, 40(2), 150-159.

Peixoto, A. D. L. A. (2016). Regulação e controle ético de pesquisa em Psicologia Organizacional e do Trabalho. Revista Psicologia Organizações e Trabalho, 16(4), 324-332.

Pessalacia, J. D. R., \& Oliveira, C. R. R. (2011). Entrevistas e questionários: uma análise Bioética sobre riscos em pesquisa. Revista de Enfermagem do Centro-Oeste Mineiro, 1(3), 422- 428.

Rippel, J. A., Medeiros, C. A. D., \& Maluf, F. (2016). Declaración Universal sobre Bioética y Derechos Humanos y Resolución CNS 466/12: análisis comparativo. Revista Bioética, 24(3), 603-612.

Resolução CNS no 1, de 13 de junho de 1988 (1988). Aprovar as normas de pesquisa em saúde. https://conselho.saude.gov.br/resolucoes/1988/Reso01.doc

Resolução CNS $n^{o}$ 466, de 12 de dezembro de 2012 (2012). Diretrizes e normas regulamentadoras de pesquisas envolvendo seres humanos. https://conselho.saude.gov.br/resolucoes/2012/Reso466.pdf

Resolução CNS $n^{\circ} 196$, de 10 de outubro de 1996 (1996). Aprovar as seguintes diretrizes e normas regulamentadoras de pesquisas envolvendo seres humanos. https://www.inca.gov.br/publicacoes/legislacao/resolucao-cns-196-96

Resolução CNS $n^{\circ}$ 510, de 7 de abril de 2016 (2016). Dispõe sobre as normas aplicáveis a pesquisas em Ciências Humanas e Sociais. Diário Oficial da União. http://bvsms.saude.gov.br/bvs/saudelegis/cns/2016/res0510_07_04_2016.html

Sarti, C. (2015). A ética em pesquisa transfigurada em campo de poder: notas sobre o sistema CEP/Conep. Revista Brasileira de Sociologia-RBS, 3(5), 79-96.

Sass H.M. (1983). Reichsrundschreiben 1931: pre-Nuremberg German regulations concerning new therapy and human experimentation. $J$ Med Philos. May;8(2):99-111.

Silva, É. Q., \& Portela, S. C. O. (2017). Ética em pesquisa: análise das (in) adequações do atual sistema de revisão ética concernentes à pesquisa social. Revista Mundaú, (2), 38-53. 
Research, Society and Development, v. 10, n. 7, e23110715917, 2021

(CC BY 4.0) | ISSN 2525-3409 | DOI: http://dx.doi.org/10.33448/rsd-v10i7.15917

Silveira, D. T., \& Córdova, F. P. (2009). A pesquisa científica. In: Gerhardt, T. E., \& Silveira, D. T. [Org.]. Métodos de pesquisa. : Editora da UFRGS, 2009. $33-44$.

Souza, T. R. P. (2008). A experimentação com seres humanos e a ajuda de custo ao sujeito de pesquisa. Direito UNIFACS - Debate Virtual, 101(101).

Taquette, S. R., \& Borges, L. (2021). Pesquisa qualitativa para todos. Editora Vozes.

Thomasi, T. Z. (2016). Comitês de Ética em Pesquisa: Da linguagem técnico-científica à normatização. Cadernos Ibero-Americanos de Direito Sanitário, 5(3), $10-30$.

Witiuk, I. L., França, B., Krüger, C., \& Guebert, M. C. C. (2018). Ética em pesquisa envolvendo seres humanos. PUCPRess. 